\title{
Factor Analysis of Acute Ward Nurses' Concepts of Life and Death
}

\author{
Yusuke Sakurai ${ }^{1}$, Miwa Yamamoto ${ }^{2}$ \\ ${ }^{1}$ Nara Medical University Basic Nursing Science, Nara, Japan \\ ${ }^{2}$ Department of Adult and Elderly Nursing, School of Health Sciences, Faculty of Medicine, Tottori University, Yonago, Japan \\ Email: y.sakurai@naramed-u.ac.jp, tokiwa27@hotmail.com
}

How to cite this paper: Sakurai, Y. and Yamamoto, M. (2018) Factor Analysis of Acute Ward Nurses' Concepts of Life and Death. Open Journal of Nursing, 8, 629-639. https://doi.org/10.4236/ojn.2018.89047

Received: August 6, 2018

Accepted: September 10, 2018

Published: September 13, 2018

Copyright $\odot 2018$ by authors and Scientific Research Publishing Inc. This work is licensed under the Creative Commons Attribution International License (CC BY 4.0).

http://creativecommons.org/licenses/by/4.0/ (c) (i) Open Access

\begin{abstract}
Background: The Ministry of Public Management, Home Affairs, Posts and Telecommunications announced that the proportion of elderly people aged 65 or over in the total population of Japan reached a record high of $26.7 \%$ in the present Japan. Aims: This paper aimed to clarify from acute ward nurses' concepts of life and death in Japan. Methods: Questionnaires were distributed to 720 nurses working in acute care hospital A in the Kansai area in Japan. Distribution destinations were all wards except for operating rooms and outpatient clinics. We initially classified the 27 items from Hirai et al.'s death and life scale into the initial seven factors (via promax rotation). Operational Definition: In my analysis, I relied considerably on the seven-point Likert scale of the Concept of life and death. Ethical Considerations: The present study was approved by the Tottori University Ethics Review Committee (1603 A 156). Results: The initial factor analysis revealed that 10 of the 27 items were inadequate. Thus, a second analysis was conducted on the remaining 17 items. The $\mathrm{KMO}$ analysis produced a value of 0.8. A Bartlett's test produced a significant result ( $\mathrm{p}<0.001)$, and Cronbach's $\alpha$ was 0.8 , which was the result obtained during initial scale validity checks. The present analysis led to the extraction of 4 factors with eigenvalues greater than 1 , with a cumulative contribution rate of $62.8 \%$. Consideration: The first factor comprised all subscales except for the "death avoidance" subscale, which fit better within the fourth factor. These factors included "A comprehensive view of life and death" "Sharing the fate of death and liberation" "Death fear, anxiety, and avoidance", and "Liberation from life and a world after death".
\end{abstract}

\section{Keywords}

Anxiety, Attitude to Death, Fear, Nurses, Thanatology 


\section{Introduction}

\subsection{Background of the Japanese Aging Population}

The Ministry of Public Management, Home Affairs, Posts and Telecommunications announced that the proportion of individuals aged $65+$ throughout Japan reached a record high of $26.7 \%$ in 2016 . This demographic shift is likely the result of increased life expectancy through medical advances.

\subsection{The Current State of Life and Death Education for Nursing Practice}

Education regarding post-mortem treatment in Japan is conducted in $75.2 \%$ of schools. Primary lesson methods include lectures, viewing VTRs, and discussing hands-on experience, and operation time accounts for a sizable proportion of class time (i.e., for those that run for 90 minutes). Education on post-mortem treatment in Japan is not available for around 25\% of schools. Reasons for this include, "other items are given priority", "not enough time available", and "post-mortem training is done on-clinical site" (Hirano [1]).

The number of patients over the age of 65 undergoing surgery has increased year by year [2]. Based on a population survey conducted by the Ministry of Health, Labor and Welfare in Japan, $80.3 \%$ of people die at hospitals or clinics, with only about $12 \%$ of Japanese residents dying at home [2]. Thus, nurses working at acute care hospitals frequently experience patient mortality, providing ample opportunities for thinking about death.

Based on these aforementioned details, education regarding death is important for nursing practice. However, such educational opportunities are quite limited, as noted by Hirano et al., whereby only $75.2 \%$ of nursing schools provide education regarding post-mortem treatment. Furthermore, when education is provided, it is not addressed extensively during 90-minute sessions.

"Hence, many nurses are puzzled by how to aid patients who are at the end of life, as well as the appropriate attitudes needed regarding terminal care and death." Oyama [3]. Additionally, cultural shifts in the Japanese nuclear family has changed the exposure nurses have to death experiences in their day-to-day lives. Thus, nurses may experience death for the first time in their lives when witnessing a patient's death. Furthermore, there is little research in this area. One prior study focused on life and death attitudes among nurses working on terminal wards, but little else is available.

Therefore, the present analysis was conducted to assess attitudes toward life and death among nurses working on acute care hospital wards in Japan.

1) Definition of terms

Thanatology is "a way of thinking about life and death." Yamamoto [4] mentioned that one's view of life and death is a fundamental human value that does not change throughout one's lifetime. This viewpoint develops throughout the lifespan, and some motivational components are important. In the present study, the idea of life and death was defined as a "way of thinking about how to 
live and how to die."

2) Review of literature on life and death based on Hirai et al. [5]

Several measures, such as the DAS (Death Anxiety Scale; Templer [6]) and Death Attitude Profile-revised method (DAP-R; Wong et al. [7]) have been developed to measure life and death conceptions. However, few studies have quantitatively measured Japanese individuals' life and death views.

Hirai and colleagues developed a new measure for assessing Japanese views of life and death. Surveys of this nature are generally devised for college and vocational school students, and scale reliability has been previously addressed. High reproducibility has been observed across factors. Thus, basic life/death scale factors are highly reliable. The scale assessed in the present study comprised 7 factors: 1) belief in an afterlife, 2) death anxiety, 3) death relief, 4) death avoidance, 5) life purpose, 6) death concern, and 7) supernatural beliefs. Furthermore, reliability and validity of this scale has been previously confirmed.

\section{Aims}

The main aim of the present study was to clarify the factor structure of a life and death scale for female nurses working in acute care wards in Japan.

\section{Materials and Methods}

1) Question content and data analytic method

Basic participant attributes (i.e., years of experience, age, gender; Table 1) were assessed in addition to factors underlying life and death conceptualizations. Items were rated on 7-point Likert scales [5]. The scale comprised 27 items across the seven subscales (Table 2) [8]. Permission was granted from the questionnaire's author. Further, informed consent among participants was also distributed along with a questionnaire form.

In terms of data analyses, we first examined basic demographic statistics. Next, an exploratory factor analysis for death and longevity scores (promax rotation, main factor method) was conducted. This analysis extracted factors with an eigenvalue greater than 1 and factor loadings greater than 0.4. Factors that were difficult to interpret were excluded. From the above10 items were judged as no correlation from the factor coefficients.

Those with a factor loading factor of 0.4 or less were excluded, and analysis was conducted again for the remaining 17 items.

The scores of each factor represent the strength of consciousness, respectively, and factor analysis was carried out by assuming the Likert scale as an interval scale.

IBM SPSS Statistical Package for the Social Sciences for WINDOWS was used for all analyses.

And significance was set at $\mathrm{p}<0.05$ (two tailed).

2) Sample size

The sample size was $95 \%$ confidence level, it was calculated assuming that everyone answered, and it turned out that 385 or more was necessary. 
Table 1. Investigate the items about the basic attributes.

Please circle the corresponding item and fill in the contents in ( )

1. Please tell me the years of nursing experience. ( ) Year

2. will ask you about the clinical department experienced so far. Please fill in the years of experience in the following ( ).

Department of Rehabilitation Medicine ( ) Department of Rehabilitation（ ） Psychiatry Department of Neurology and Neurosurgery

Department of Pediatrics（ ） Department of Obstetrics and Gynecology（） Kidney Internal Medicine and Surgery Urology Department of Orthopedic and Orthopedic Surgery ( ) ICU.CCU.SCU ( )

3. Please tell me your age. $\rightarrow(\quad$ ) year old

4. Which is your gender? $\rightarrow 1$. Male 2 . Female

5. Have you ever lost your close relatives (including friends and lovers)? $\rightarrow 1$. Yes 2 . No

6. Are you experienced nursing with close relatives who are near death? $\rightarrow 1$. Yes 2 . No

7. Have you taken charge of the terminal (terminal) patient in the ward? $\rightarrow 1$. Yes 2 . No

I will ask you who answered "Yes" in 6 . Have you experienced death of the patient you served?

$\rightarrow 1$. Yes 2. No. 3. I do not know.

8. Is there a religion of religion? $\rightarrow 1$. Yes 2 . No. 3. Neither

9. As a nurse do you think that there is a necessity for patients in the late stage to believe in religion? $\rightarrow 1$. Yes 2 . No 3. Neither

10. Do you think patients receive their own death acceptance by religious beliefs?

$\rightarrow$ 1. Yes 2. No. 3. Neither

11. Do you think that a patient believes religion will be a patient's own spiritual support? $\rightarrow$ 1. Yes 2. No. 3. Neither

12. Have you ever thought about thinking about death? $\rightarrow 1$. Yes 2 . No 3. do not know

13. I will ask you who answered yes. What is the trigger?

Please circle all that apply.

1. Death of an important person or a familiar person (pet) 2. Media such as television 3. Book 4. University Lecture 5. Practical training6. Movie 7. I do not remember 8. Other ( )

14. Is there an opportunity to talk about death with friends and parents? $\rightarrow 1$. Yes 2. No. 3. I do not know.

15. About the image of death $\rightarrow 1$. Good ones 2. Anything better to say 3. Neither 4. Somewhat bad 5. Bad ones

16. Were there classes (practical training) about treatment after death during nursing student days? $\rightarrow 1$. Yes 2 . No 3 . do not know

III If you have any opinions or comments about nurse's view on death or life, or if you have any comments or suggestions on this research, please fill in freely

Table 2. Death attitude inventory.

[1. Afterlife belief]

I think that there is the next world

I think that there are "soul" and "curse" in this world

I think that a soul remains although dies

People are supposes as a postmortem and an again birth vary

[2. Death anxiety]

Dying is dreadful

I think that I turn uneasy about dying

I think that death is a terrifying thing

I fear death very much

[3. Death relief] 


\section{Continued}

I think that death is released from pain in this world

I regard death as the relief from the pressure of this life

Death is in pain with a pain and is a relief of a valve

Death brings about a spiritual relief

[4. Death avoidance]

I avoid considering death

No matter what it may carry out, I would like to avoid considering death

I am going to eliminate it, whenever the view about death occurs

I am trying to seldom consider death by that of a terrifying

[5. Life purpose]

I have found out the mission and the purpose which were clearly made into life

For me, the power to find out the significance of life, the purpose, and a mission is an exist to a sufficiently

The reason for an alive has clarified in this way now with the consider about my life here

The future is bright

[6. Death concern]

I think well what am I with death?

I think about my death well

I think about a familiar person's death well

I often talk about a household, a friend, and death

[7. Supernatural belief]

People's span of life considers beforehand "I am decided by it"

A span of life is a suppose as having been decided from the original

People's life and death are decided by the power (a fate, God, etc.) which is not a foregone conclusion

From: A survey of the death attitude of pharmacy students finished clinical training using the Death Attitude Inventory Palliative Care Research 2013; $8(2): 319-25$.

There are 840 nurses working in the hospital.

Questionnaires were distributed to 720 nurses working in acute care hospital A in the Kansai area. Distribution destinations were all wards except for operating rooms and outpatient clinics.

3) Research timeline

The time required for survey completion was about 10 to 15 minutes, including explanations and informed consent. The research implementation period was from April 2016 to March 2017 (registration deadline: January 2017).

4) Ethical consideration

After describing the purpose of the study, orally and in writing, to the nursing manager of the particular facility, we distributed questionnaires to the target hospital nursing department, ward manager, and individual nurses. In a written statement, we documented that all data collected was only for research purposes. We also ensured that participants' privacy would be protected.

In order to ensure privacy, individual nurses were given an anonymous envelope that would be sealed (by the nurse) and placed in a rest room box within 2 to 3 weeks after administration. The present study was approved by the Tottori University Ethics Review Committee (1603 A 156). 


\section{Results}

1) Collection status and participant characteristics

Of the 720 questionnaires distributed, 405 were completed (56.2\%). As our analyses were focused solely on female respondents, questionnaires from 30 men (17\%) were excluded, leaving us with a total of 370 valid questionnaires (83\%) [9] (Table 3).

Average participant age was 34.8 years $(\mathrm{SD} \pm 11.7$; range $=21$ to 64$)$, and average nursing experience was 12.0 years $(S D= \pm 10.8$; range $=1$ to 42 years; Table 4). Two hundred students graduated from professional and vocational schools (54.0\%), 110 from universities (29.8\%), 46 from junior colleges (12.4\%), 10 from high school nursing departments (2.7\%), and 4 from graduate schools (1.1\%; Table 5).

2) Confirming scale reliability and validity

The Kaiser-Meyer-Olkin value (hereinafter referred to as the KMO value) was 0.8 ; a Bartlett's test produced a significant result $(\mathrm{p}<0.001)$, and the $\alpha$ coefficient was 0.8 . Hence, scale reliability and validity was initially confirmed with the present sample.

3) Factor analysis of nurses' views on life and death

We initially classified the 27 items from Hirai et al's death and life scale into the initial seven factors (via promax rotation). The initial factor analysis revealed that 10 of the 27 items were inadequate. Thus, a second analysis was conducted on the remaining 17 items. The KMO analysis produced a value of 0.8. A Bartlett's test produced a significant result $(\mathrm{p}<0.001)$, and Cronbach's $\alpha$ was 0.8 , which was the result obtained by Hirai et al. during initial scale validity checks. The present analysis led to the extraction of 4 factors with eigenvalues greater than 1 , with a cumulative contribution rate of $62.8 \%$ (Table 6).

Table 3. Sex difference.

\begin{tabular}{cccccc}
\hline & Category & N (person) & $\%$ & Age & SD \\
\hline Sex & Male & 30 & 7.4 & 32.7 & 7.63 \\
& Female & 370 & 91.4 & 34.8 & 11.7 \\
& No answer & 5 & 1.2 & 5 & \\
Total & 405 & 100 & & \\
\hline
\end{tabular}

Table 4. Age and nursing experience years.

\begin{tabular}{cccccc}
\hline & $\begin{array}{c}\text { Average } \\
\text { value }\end{array}$ & Median & SD & $\begin{array}{c}\text { Minimum } \\
\text { value }\end{array}$ & $\begin{array}{c}\text { Maximum } \\
\text { value }\end{array}$ \\
\hline $\begin{array}{c}\text { Age (years) } \\
\text { Nurse experience } \\
\text { years (years) }\end{array}$ & 34.8 & 32 & \pm 11.7 & 21 & 64 \\
Nurse experience years & 12.0 & 8 & \pm 10.8 & 1 & 42 \\
& $\begin{array}{c}1 \text { to } 4 \\
\text { (Year) }\end{array}$ & $\begin{array}{c}5 \text { to } 8 \\
\text { (Year) }\end{array}$ & $\begin{array}{c}\text { 9 to } 12 \\
\text { (Year) }\end{array}$ & $\begin{array}{c}13 \text { to that's all } \\
\text { (Year) }\end{array}$ & \\
$\begin{array}{c}\text { Number of people } \\
\text { (people) }\end{array}$ & 112 & 64 & 59 & 170.0 & \\
\hline
\end{tabular}


Table 5. Comparing by school graduation.

\begin{tabular}{|c|c|c|c|c|c|}
\hline & Category & $\mathrm{N}$ (person) & $\%$ & Age & $\mathrm{SD}$ \\
\hline \multirow{7}{*}{$\begin{array}{l}\text { Graduated nursing } \\
\text { education institution }\end{array}$} & High school nursing department & 10 & 2.7 & 34.6 & 13.9 \\
\hline & professional and vocational school & 200 & 54 & 38.1 & 11.7 \\
\hline & Junior college & 46 & 12.4 & 39.0 & 10.8 \\
\hline & university & 110 & 29.8 & 26.6 & 5.9 \\
\hline & graduate school & 4 & 1.1 & 41 & 5.1 \\
\hline & no answer & 0 & 0 & & \\
\hline & total & 370 & 100 & & \\
\hline
\end{tabular}

Table 6. factor analysis of seventeen subjects with death and life observation and Cronbachs coefficient $\alpha$.

\begin{tabular}{|c|c|c|c|c|}
\hline & \multicolumn{3}{|c|}{ factor } & \multirow[b]{2}{*}{4} \\
\hline & 1 & 2 & 3 & \\
\hline I think about my death well & 0.85 & -0.18 & 0.01 & -0.02 \\
\hline People's span of life considers beforehand "I am decided by it" & 0.77 & -0.04 & 0.17 & -0.06 \\
\hline I think that death is released from pain in this world & 0.76 & -0.13 & 0.15 & -0.03 \\
\hline I have found out the mission and the purpose which were clearly made into life & 0.69 & 0.04 & -0.07 & 0.02 \\
\hline I think that there is the next world & 0.69 & 0.20 & -0.18 & 0.03 \\
\hline A span of life is a suppose as having been decided from the original & 0.65 & 0.12 & -0.03 & -0.03 \\
\hline I think that death is a terrifying thing & 0.62 & 0.08 & -0.19 & 0.08 \\
\hline People's life and death are decided by the power (a fate, God, etc.) which is not a foregone conclusion & 0.01 & 0.80 & 0.01 & 0.01 \\
\hline Death is in pain with a pain and is a relief of a valve & 0.00 & 0.74 & 0.03 & -0.03 \\
\hline I often talk about a household, a friend, and death & 0.05 & 0.73 & 0.08 & 0.02 \\
\hline I think that I turn uneasy about dying & -0.04 & 0.07 & 0.76 & -0.07 \\
\hline I avoid considering death & -0.06 & -0.02 & 0.70 & -0.03 \\
\hline No matter what it may carry out, I would like to avoid considering death & -0.14 & 0.03 & 0.58 & 0.06 \\
\hline I think that there are "soul" and "curse" in this world & 0.21 & 0.06 & 0.53 & 0.12 \\
\hline $\begin{array}{l}\text { For me, the power to find out the significance of life, the purpose, } \\
\text { and a mission is an exist to a sufficiently }\end{array}$ & 0.01 & -0.04 & -0.04 & 0.73 \\
\hline I regard death as the relief from the pressure of this life & 0.03 & -0.07 & 0.08 & 0.72 \\
\hline I think that a soul remains although dies & -0.05 & 0.11 & 0.00 & 0.56 \\
\hline Initial eigenvalues & 4.55 & 2.51 & 2.08 & 1.55 \\
\hline Cumulative contribution rate (\%: first factor to fourth factor & 26.74 & 41.50 & 53.74 & 62.87 \\
\hline Bartlett's test & & $* * *$ & & \\
\hline Seventeen subjects's Cronbachs coefficient $\alpha(\mathrm{n}=370)$ & & 0.81 & & \\
\hline
\end{tabular}

Promax rotation, main factor method $\mathrm{n}=370 \mathrm{KMO}=0.802$, Rotation method: Promax method with Kaiser's normalization, ${ }^{\star * \star}=\mathrm{p}<0.001$

The first factor was called, "A comprehensive view of life and death" and comprised the following seven items: "I think about my death," "People's span of 
life considers beforehand I am decided by it." "I think that death releases pain from this world." "I have found out the mission and purpose of life." "I think that there is an afterlife." "A lifespan is decided from the original." "I think that death is a terrifying thing."

The second factor was called, "Sharing the fate of death and liberation," and comprised the following three factors: "People's life and death are decided by a higher power (fate, God, etc.), which is not a foregone conclusion," "Death is pain, and this pain can be relieved," "I often talk about a household, a friend, and death."

The third factor was called, "Death fear, anxiety, and avoidance," and comprised the following four items: "I am uneasy about dying," "I avoid considering death," "No matter what, I would like to avoid considering death," "I think that there are 'souls' and 'curses' in this world."

The fourth factor was called, "Liberation from life and a world after death," and comprised the following three items: "For me, significance in life, purpose, and mission includes existing sufficiently," "I regard death as relief from the pressure of this life," "I think that a soul remains even when one dies."

In the present study, we examined life and death views with respect to the death of one's relatives; however, there were no significant differences regarding factor composition. Furthermore, there were no differences in terms of item composition based on years of nursing experience.

\section{Discussion}

\section{1) Response rates}

We obtained suitable response rates from the target hospitals, wards, and nurses. Yoshida et al. [10] and Takigawa [11] also collected questionnaires using the same death and life scale used in the present study, observing response rates of $70 \%$ to $80 \%$, respectively. Our present response rate was $56.2 \%$; one possibility for this lower rate could have been the relative short data collection period implemented. Additionally, a survey from the Japan Nursing Association revealed that ward nurses' weekly overtime work often exceeds 12 hours [12]. Thus, a ward nurse's busy work schedule may limit the time available to complete a survey. Thus, future work should consider questionnaire content and number of items to help facilitate greater response rates.

2) Participant characteristics.

According to a survey from the Japan Nursing Association, the average age of acute ward nurses was 34.8 years old, which is similar to the present sample [13] (Table 3 and Table 5). Furthermore, years of experience and education background was comparable between our sample and what was observed within the prior Japan Nursing Association survey.

3) Scale results

The concept of death and life scale (Hirai et al.) demonstrated adequate reliability and validity based on Cronbach's $\alpha, \mathrm{KMO}$, and Bartlett's test results. However, our factor analysis suggested that a better fit to the data was obtained 
through a 17 -item, rather than the original 27 -item, scale.

4) Nurses' concepts of life and death

The first factor extracted was, "A comprehensive view of life and death." This factor comprised all characteristics other than "death avoidance," which fit better within our fourth factor. Furthermore, when compared to factors derived from previous studies assessing nurses' views of life and death (i.e., Hirai et al.), our factors were constructed from various viewpoints, rather than from a constrained framework.

The second factor was termed, "Sharing the fate of death and liberation," which comprised three items. This concept argues that life and death are not voluntary actions, and death is a liberation from the pain and suffering experienced while living. Furthermore, death experiences and anxiety can be shared with family and friends.

Thethird factor was named, "Death fear, anxiety, and avoidance," which comprised four items. This factor not only dealt with fear surrounding death, but there was also a spiritual component (i.e., "I think that there are spirits and talents in the world").

Finally, the fourth factor was, "Liberation from life and a world after death," which comprised three items. Content included living with a purpose and being released from life after death. This concept focused on the shirking of burdens through entry into an afterlife.

Previous studies from Oyama et al. [3] and Negishi et al. [14] revealed that items assessing death avoidance were endorsed less frequently than in the present study. Furthermore, Okamoto et al. [15] observed that clinical nurses believe in a post-mortem world and have a greater fear of death when younger. However, in the present study, age and years of nursing experience did not influence death anxiety endorsement. Such a result could be described based on a multifaceted view of life and death. Through contact with death during one's early career stages (e.g., 1st and 2nd year working in an acute ward), avoidance is limited, and death concepts can be formulated more fully. Furthermore, nurses have diverse perspectives regarding life and death. This is exemplified by the fact that the factor loadings observed in the present study for each subscale were different from what has been observed in previous studies. However, Tange [16] argues that indirect death experiences can help shape one's views of life and death. Opportunities for experiencing people close to death are also influential. In other words, opportunities to indirectly learn about death are important. Thus, future work should expand upon nursing education, postgraduate education, and preparatory education in order to bolster and formulate nurses' adaptive views of life and death.

\section{Conclusion}

We surveyed female nurses $(n=370)$ from acute wards using a questionnaire based on Hirai et al.'s death and life scale. A factor analysis (promax rotation) revealed a 4 -factor structure. The first factor comprised all subscales except for 
the "death avoidance" subscale, which fit better within the fourth factor. These factors included "A comprehensive view of life and death" "Sharing the fate of death and liberation" "Death fear, anxiety, and avoidance", and "Liberation from life and a world after death".

\section{Limitations and Future Directions}

A few study limitations should be noted. First, the present survey was only conducted at one facility, limiting generalizability of our findings. Future work is needed that includes additional facilities and departments (i.e., chronic and palliative care wards, etc.). Other characteristic factors should also be considered in the future, such as sex differences, patient disease and symptom profiles, patient age, etc., to more comprehensively determine how nurses' views of life and death emerge. Finally, a larger and more diverse participant sample would be useful for expanding nurses' manifestation of life and death viewpoints.

\section{Acknowledgments}

We deeply appreciate cooperation from the nursing departments and wards sampled, along with Professor Yamamoto Miwa, Professor Masami Chujo, and Professor Kumiko Sasaki, for their guidance.

\section{Conflicts of Interest}

The authors declare no conflicts of interest regarding the publication of this paper.

\section{References}

[1] Yuko, H. (2013) Attitudes towards Terminal Care and Death of Faculty Who Teach Post-Mortem Treatment Education and Post-Mortem Treatment in Basic Education. (shigo no chiryokyoiku to shigo no kisokyoiku o shidosurukyoin no shumatsukaigo to shibonitaisurutaido, shi to shinikansururinshokenkyu). Clinical Research on Death and Dying, 36, 169-174.

[2] Ministry of Health and Welfare. Health and Welfare White Paper (2010) Annual Report on Population Dynamics Statistics of Death. Table 5 Annual Trends of Deaths and Composition Ratios by Location of Death.

[3] Yukiko, O. (2003) A Comparative Study on Nursing and Nursing Students' View on Life and Death. (Kango-shoku to kangogakusei no shiseikan no keikonikansuruhikakukenkyu). The 34th Annual Meeting of the Japanese Society of Nursing, 77.

[4] Shunichi, Y. (1992) Recommendation of Death and Life Study, IGAKU-SHOIN, Tokyo.

[5] Kei, H., Yukihiro, S., Sachihi, A., et al. (2000) Study on View on Death and Life Study on the Life and Death Scale and Its Reliability and Validity. (Shiseikannikansurukenkyushiseikanshakudo no kosei to shinrai-sei datosei no kensho). Clinical Research on Death and Dying, 23, 71-76.

[6] Templer, D.A. (1970) The Construction and Validation of a Death Anxiety Scale. Journal of General Psychology, 82, 165-177. https://doi.org/10.1080/00221309.1970.9920634 
[7] Wong, P.T.P., Reker, G.T. and Gesser, G. (1994) Death Attitude Profile-Revised: A Multidimensional Measure of Attitudes toward Death. In: Neimeyer, R.A., Ed., Death Anxiety Handbook. Research, Instrumentation, and Application, 121-148.

[8] Sugiura, M., Kuroda, S., et al. (2013) A Survey of the Death Attitude of Pharmacy Students Finished Clinical Training Using the Death Attitude Inventory. Palliative Care Research, 8, 319-325.

[9] Japan Mathematical Society (2007) Mathematical Dictionary. Iwanami Shoten, Tokyo.

[10] Yoshida, K., Ishida, K., Seyama, K., et al. (2009) Comparison of the View of Life and Death of Doctors and Nurses Working at University Hospitals. (Daigakubyoinnikinmusuruishi to kangoshi no shiseikan no hikaku). Journal of Japanese Cancer Nursing Association, 21, 1-9.

[11] Takigawa, A. (2014) Analysis of Viewpoint of Death and Life of a Hospital Nurse in Life and Death Scale. (Shiseikan shakudoniokeru A byoinkangoshi no shiseikan no bunseki). Papers of the Japan Nursing Association Nursing Comprehensive, 44, 182-184.

[12] Public Benefit Organization, Japan Nursing Association (2014) Survey on Wages of Nurses in Hospital 2012.

[13] Public Benefit Organization, The Japan Nursing Association (2016) Nursing Relationship Statistics Collection.

[14] Negishi, K. and Nakamura, M. (2014) Characteristics of Clinical Nurse's View on Life and Death and Care. (Rinshokangoshi no shiseikan to mitori kea no tokucho). Yamanashi University Nursing Association Journal, 12, 15-20.

[15] Okamoto, F. and Ishii, K. (2005) Factor Analysis of Nurse's View on Life and Death and Influence on Scale. (Kangoshi no shiseikanshakudosakusei to shakudonieikyowooyobosuyoinbunseki). Journal of Japanese Society for Nursing Research, 28, 53-59.

[16] Takako, T. (1995) Development of View on Life and Death. (Shiseikan no tenkai). Bulletin of the Faculty of Education, Nagoya University, 42, 149-156. 